\title{
PENGUKURAN SPEKTRA NEUTRON PADA TABUNG BERKAS RADIOGRAFI NEUTRON REAKTOR G.A. SIWABESSY DENGAN SINGLE SPHERE SPECTROMETER
}

\section{MEASUREMENTS OF NEUTRON SPECTRA AT A NEUTRON RADIOGRAPHY BEAMPORT OF THE G.A. SIWABESSY REACTOR BY USING SINGLE SPHERE SPECTROMETER}

\author{
Rasito $^{1}$, Bunawas 2 , U. Tarmulah ${ }^{3}$, S. Zanuar ${ }^{3}$, dan D. Andrega ${ }^{3}$ \\ ${ }^{1}$ Pusat Sains dan Teknologi Nuklir Terapan - BATAN, Jl. Tamansari 71 Bandung \\ 2 Pusat Teknologi Keselamatan dan Metrologi Radiasi - BATAN, JI. Lebak Bulus No.49 Jakarta Selatan \\ 3Pusat Sains dan Teknologi Bahan Maju - BATAN, Komplek Puspiptek Tangerang Selatan \\ E-mail: rasito@batan.go.id
}

Diterima 28 Mei 2018, diterima dalam bentuk perbaikan 26 Juli 2018, disetujui 15 Agustus 2018

\begin{abstract}
ABSTRAK
Pengukuran spektrum neutron pada tabung berkas radiografi neutron reaktor G.A. Siwabessy dengan single sphere spectrometer. Telah dilakukan pengukuran spektrum neutron pada keluaran tabung berkas neutron fasilitas radiografi neutron reaktor G.A Siwabessy. Pengukuran dilakukan untuk mengkonfirmasi adanya faktor penyebab menurunnya kualitas ketajaman citra radiografi. Pengukuran spektrum neutron dilakukan dengan menggunakan single sphere spectrometer (SSS) yang terdiri atas tujuh detektor keping emas. Tampilan spektrum neutron dari konversi aktivitas detektor SSS dibuat dengan menggunakan software UMG 3.3, adapun fungsi respon detektor SSS dihitung dengan menggunakan software MCNPX. Dari hasil pengukuran diperoleh spektum neutron yang didominasi neutron termal dengan fluks $6,14 \times 10^{6} \mathrm{n} \mathrm{cm}^{-2} \mathrm{~s}^{-1}(57 \%)$. Selebihnya adalah neutron epitermal dengan fluks $1,18 \times 10^{6} \mathrm{n} \mathrm{cm}^{-2} \mathrm{~s}^{-1}$, dan neutron cepat dengan fluks $3,37 \times 10^{6} \mathrm{ncm}^{-2} \mathrm{~s}^{-1}$. Hasil tersebut mengkonfirmasi bahwa terjadi penurunan fluks neutron termal di ujung tabung berkas radiografi neutron dari $9,2 \times 10^{6} \mathrm{n}$ $\mathrm{cm}^{-2} \mathrm{~s}^{-1}$ menjadi $6,14 \times 10^{6} \mathrm{n} \mathrm{cm}^{-2} \mathrm{~s}^{-1}$, yang diduga menjadi salah satu penyebab menurunnya kualitas ketajaman citra radiografi.
\end{abstract}

Katakunci: spektra neutron, SSS, radiografi neutron, reaktor G.A Siwabessy

\section{ABSTRACT}

Measurements of the neutron spectra at the neutron radiography beamport of the G.A. Siwabessy reactor by using single sphere spectrometer. Neutron spectra measurements have been performed at the end of the neutron beam tube of G.A Siwabessy reactor. Measurement was done to confirm the cause of the decreased quality of image sharpness resulting from radiography. The measurements of the neutron spectra were performed using a single sphere spectrometer (SSS) with seven gold foil detectors. The display of neutron spectra based on the conversion of SSS detectors activities were done using UMG 3.3 unfolding software, while the neutron response function of the SSS detector was calculated by using MCNPX computer code. From the measurement results, it is obtained neutron spectra which is dominated by thermal neutrons with flux of $6,14 \times 10^{6} \mathrm{n} \mathrm{cm}^{-2} \mathrm{~s}^{-1}(57 \%)$. The rest are epithermal neutrons with a flux of $1,18 \times 10^{6} \mathrm{n} \mathrm{cm}^{-2} \mathrm{~s}^{-1}$, and fast neutrons with flux of $3,37 \times 10^{6} \mathrm{n} \mathrm{cm}^{-2} \mathrm{~s}^{-1}$. The results confirm that neutron thermal flux decrease at the end of the neutron radiographic beam tube from $9,2 \times 10^{6} \mathrm{n} \mathrm{cm}^{-}$ ${ }^{2} \mathrm{~s}^{-1}$ to $6,14 \times 10^{6} \mathrm{n} \mathrm{cm}^{-2} \mathrm{~s}^{-1}$, where this could be one of reasons for the declining quality of radiographic image sharpness.

Keywords: neutron spectra, SSS, neutron radiography, G.A Siwabessy reactor

\section{PENDAHULUAN}

$\mathrm{R}^{\mathrm{e}}$ eaktor nuklir merupakan salah satu penghasil neutron yang dimanfaatkan untuk kegiatan riset maupun aplikasi di bidang industri. Neutron merupakan partikel tak bermuatan di dalam inti atom yang diketemukan pertama kali oleh James Chadwick pada tahun 1932 [1]. Selain merupakan partikel tak bermuatan, neutron memiliki rentang energi yang sangat lebar dari orde electron Volt (eV) hingga Giga electron Volt $(\mathrm{GeV})$. Energi neutron terbagi menjadi neutron termal (lambat), epitermal, dan cepat. Energi neutron dapat berubah setelah mengalami peristiwa tumbukan. 
Salah satu pemanfaatan neutron yang dihasilkan reaktor nuklir G.A Siwabessy adalah untuk uji tak merusak dengan teknik radiografi neutron menggunakan fasilitas sebagaimana diperlihatkan pada Gambar 1. Sifat gelombang dari partikel neutron dapat dimanfaatkan untuk membuat citra struktur mikro suatu material. Dalam aplikasi tersebut, intensitas fluks dan energi neutron sangat berpengaruh terhadap kualitas citra yang dihasilkan. Radiografi neutron adalah suatu teknik pengujian bahan yang sangat efisien tanpa merusak bahan yang diuji dan memiliki kelebihan dibandingkan dengan teknik radiografi sinar-x karena neutron dapat diatenuasi dengan baik oleh bahan khususnya yang mengandung unsur ringan seperti hidrogen, boron dan karbon[2]. Namun akhir-akhir ini kualitas hasil pengukuran dengan fasilitas radiografi neutron reaktor nuklir G. A Siwabessy tersebut mengalami penurunan sehingga menghasilkan citra radiografi yang kurang tajam. Penurunan kualitas citra ini diduga karena adanya perubahan fluks neutron termal sehingga pengukuran ulang menjadi urgen untuk dilakukan dalam rangka mengkonfirmasi penyebab penurunan kualitas tersebut.

Pengukuran fluks neutron termal dan epitermal di dalam fasilitas radiografi neutron PSTBM - BATAN pada reaktor nuklir G. A Siwabessy telah dilakukan pada tahun 2008 dengan menggunakan detektor keping emas paska modifikasi tabung kolimator fasilitas radiografi neutron berupa penambahan cincin dari bahan B4C pada pangkal tengah dan ujung lubang kolimator. Hasil pengukuran fluks neutron termal yang diperoleh pada saat itu adalah $7,9 \times 10^{5}-7,1 \times 10^{7} \mathrm{n} \mathrm{cm}^{-2} \mathrm{~s}^{-1}$ dengan rata-rata $9,2 \times 10^{6} \mathrm{n} \mathrm{cm}^{-2} \mathrm{~s}^{-1}$. Sedangkan fluks neutron epitermal diperoleh $4,2 \times 10^{5}-9,9 \times 10^{6} \mathrm{n} \mathrm{cm}^{-2} \mathrm{~s}^{-1}$ dengan rata-rata $1,4 \times 10^{6} \mathrm{n} \mathrm{cm}^{-2} \mathrm{~s}^{-1}[2]$.

Untuk mengetahui kondisi fluks neutron termal, epitermal, maupun cepat pada saat ini maka telah dilakukan pengukuran ulang. Pada umumnya, pengukuran spektrum neutron dapat dilakukan menggunakan detektor single sphere spectrometer (SSS) yang berupa bola pejal dari bahan polietilen $\left(\mathrm{CH}_{2}\right) \mathrm{n}$ dan sejumlah kepingan emas $\left({ }^{197} \mathrm{Au}\right.$ ) yang berfungsi sebagai detektor neutron.

Detektor SSS dengan desain 37 keeping emas telah dikembangkan oleh Bedogni, dkk [3,4]. BATAN juga telah mengembangkan perangkat pengukur spektrum neutron dengan detektor SSS yang lebih sederhana yaitu hanya dengan menggunakan 7 keping emas. Perangkat ini telah di uji dan dikalibrasi di PTKMR BATAN pada tahun 2015. Detektor SSS buatan BATAN ini didisain dengan hanya menempatkan 7 keping emas yang berdiameter $11 \mathrm{~mm}$ dan tebal $0,18 \mathrm{~mm}$ dengan kemurnian $99.9 \%$ di dalam bola polietilen berdiameter $30 \mathrm{~cm}$. Di dalam detektor SSS, tiap keping emas ditempatkan pada sumbu X pusat bola dengan variasi kedalaman $15 \mathrm{~cm}, 12 \mathrm{~cm}, 9 \mathrm{~cm}, 4,5 \mathrm{~cm}, 3 \mathrm{~cm}$, dan $1 \mathrm{~cm}$ sebagaimana terlihat pada Gambar 2 [5]. Variasi kedalaman keping emas tersebut diharapkan akan membedakan fluks neutron yang diterima sehingga menyebabkan bervariasinya radioaktivitas yang terbentuk akibat perbedaan keping emas yang teraktivasi melalui reaksi ${ }^{197} \mathrm{Au}(\mathrm{n}, \gamma){ }^{198} \mathrm{Au}$. Besar radioaktivitas tiap keping emas sebagai fungsi kedalaman tersebut selanjutnya diolah menjadi bentuk distribusi fluks neutron sebagai fungsi energinya (spektrum neutron). Makalah ini akan melaporkan hasil pengukuran ulang spektrum energi neutron dengan menggunakan detektor buatan BATAN tersebut.

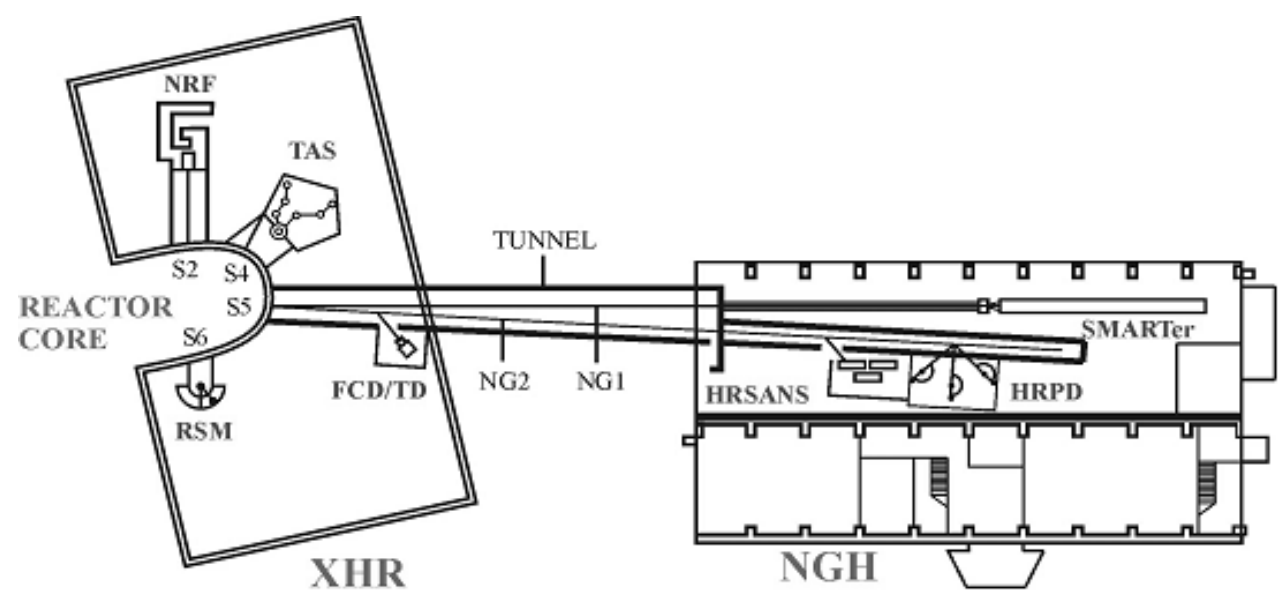

Gambar 1. Fasilitas radiografi neutron (NRF) PSTBM pada reaktor nuklir G. A Siwabessy 


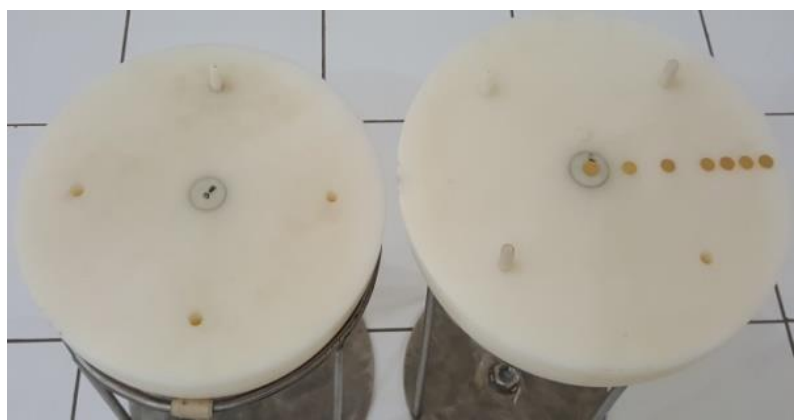

Gambar 2. Single sphere spectrometer dengan detektor 7 keping emas $\left({ }^{197} \mathrm{Au}\right)$ yang ditempatkan di sepanjang sumbu $X$ pusat bola dengan variasi kedalaman .

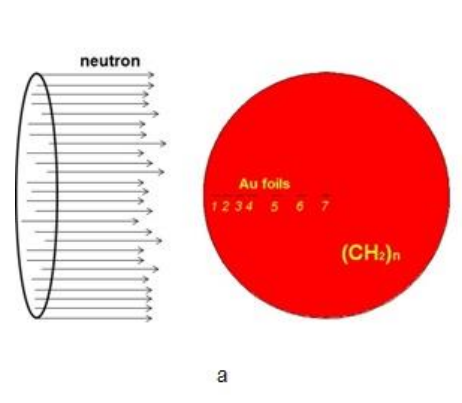

(a)

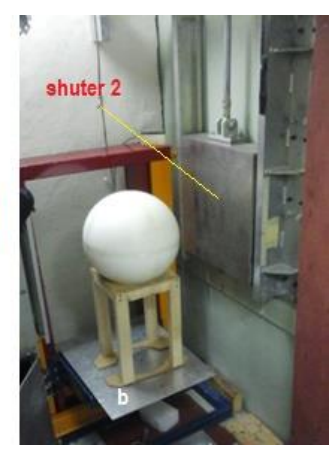

(b)

Gambar 3. (a) Arah penyinaran dan (b) Penempatan SSS di ruang sampel radiografi

\section{METODOLOGI}

Pengukuran spektrum neutron menggunakan detektor SSS dilakukan melalui tiga tahap yaitu dimulai dengan iradiasi detektor SSS, kemudian dilakukan pengukuran aktivitas keping emas yang teraktivasi oleh berkas neutron, dan terakhir dilakukan unfolding spektrum. Iradiasi detektor SSS dilakukan untuk mengaktivasi keping emas dengan posisi pada sampel radiografi. Aktivitas keping emas diukur dengan menggunakan spektrometer gamma dengan detektor HPGe milik PSTBM - BATAN dan unfolding spektrum dilakukan dengan menggunakan program UMG 3.3.

\section{Iradiasi SSS}

Iradiasi SSS dilakukan dengan menempatkannya tepat di posisi sampel radiografi neutron, dengan waktu iradiasi dimulai setelah shuter 1 dan 2 dibuka. Bagan penempatan SSS di ruang sampel radiografi diperlihatkan pada Gambar 3. Posisi detektor SSS berada paralel dengan arah berkas neutron (Gambar 3a). Pada pengukuran spektrum neutron menggunakan SSS ini kondisi reaktor dioperasikan pada daya $15 \mathrm{MW}$.

\section{Spektrometer Gamma}

Tujuh detektor keping emas yang telah teraktivasi $\left({ }^{198} \mathrm{Au}\right)$ dicacah menggunakan spektrometer gamma dengan detektor Germanium kemurnian tinggi (HPGe) milik PSTBM BATAN yang telah dikalibrasi dengan menggunakan sumber gamma standar ${ }^{226} \mathrm{Ra},{ }^{152} \mathrm{Eu},{ }^{60} \mathrm{Co},{ }^{109} \mathrm{Cd},{ }^{137} \mathrm{Cs}$, dan ${ }^{133} \mathrm{Ba}$. Dari reaksi aktivasi neutron pada detektor keping $\mathrm{Au}{ }^{197} \mathrm{Au}(\mathrm{n}, \mathrm{Y}){ }^{198} \mathrm{Au}$ menghasilkan isotop ${ }^{198} \mathrm{Au}$ yang meluruh dengan waktu paruh 2,69 hari disertai pancaran sinar gamma dengan energi $412 \mathrm{keV}$. Pada energi tersebut detektor HPGe memiliki efisiensi 0.00245 untuk geometri sumber bentuk keping pada jarak pengukuran yang sama dengan posisi sampel. Waktu pencacahan tiap keping bervariasi, disesuaikan dengan tingkat aktivitasnya, semakin kecil aktivitasnya diperlukan waktu pencacahan yang lebih lama agar nilai ketidakpastian pengukuran tetap kecil.. Untuk mendapatkan ketidakpastian di bawah $1 \%$ diperlukan hasil cacahan di atas 10.000 .

\section{Unfolding Spektrum}

Nilai aktivitas per satuan massa dari masing-masing detektor di dalam SSS selanjutnya dibentuk menjadi sebuah spektrum menggunakan teknik unfolding. Salah satu program komputer yang dapat digunakan untuk unfolding adalah UMG 3.3. Program UMG 3.3 merupakan program komputer yang 
dikeluarkan oleh Physikalisch Technische Bundesanstalt (PTB) Jerman pada tahun 2004. UMG (Unfolding dengan MAXED dan GRAVEL) adalah paket dari tujuh program yang digunakan untuk analisis data hasil pengukuran spektrometer menggunakan teknik unfolding [6]. Dengan menggunakan program UMG 3.3 ini, nilai aktivitas dari 7 keping detektor SSS diperluas (unfolding) menjadi bentuk spektrum.

Untuk menjalankan program UMG 3.3 tersebut diperlukan dua buah inputan. Inputan pertama adalah data respon matrik yang diperoleh melalui simulasi menggunakan MCNPX. Inputan kedua adalah nilai aktivitas masing-masing keping detektor SSS setelah iradiasi. Setelah semua inputan terisi, maka program UMG 3.3 dapat dijalankan dengan menggunakan sebuah komputer, dalam hal ini berupa laptop dengan processor $1,5 \mathrm{GHz}$, RAM $2 \mathrm{~GB}$ dan sistem operasi Windows 7 . Dengan komputer ini waktu yang diperlukan untuk melakukan running kurang dari 10 detik. File keluaran yang berupa fluks neutron sebagai fungsi energi selanjutnya ditampilkan dalam bentuk spektrum menggunakan perangkat lunak UMGplot.

Distribusi fluks neutron sebagai fungsi energi ditentukan berdasarkan nilai aktivitas keping-keping emas pada detektor SSS pasca iradiasi. Hubungan antara aktivitas keping-keping emas dan fluks neutron dapat dirumuskan dengan persamaan integral Fredholm orde pertama yaitu:

$A_{\text {sat }}=\int_{0}^{E} \mathrm{R}(\mathrm{E}) \Phi_{E}(E) d E$

dengan $A_{\text {sat }}$ adalah aktivitas jenuh (saturasi) per satuan massa keping emas, $\Phi_{E}$ adalah fluks neutron sebagai fungsi energi, dan $R(E)$ adalah fungsi respon detektor. Fungsi respon detektor $R(E)$ selain merupakan fungsi energi juga fungsi posisi keeping emas sehingga membentuk matriks. Oleh karena itu $\mathrm{R}(\mathrm{E})$ juga disebut dengan respon matriks. Fungsi respon i detektor SSS dirumuskan [7]:

$R_{i}(E)=\frac{s_{i} N}{\rho} \int_{0}^{E} \sigma(n, \gamma) \Phi_{E} d E$

dengan $S_{i}=\frac{\pi}{4} d_{i}^{2}\left(\mathrm{~cm}^{2}\right)$ adalah lebar berkas sumber neutron dengan diameter $d_{i}, N\left(5.88 \times 10^{22}\right.$ atom$\left.\mathrm{cm}^{-3}\right)$ adalah rapat atom $\mathrm{Au}$, dan $\rho\left(19,2 \mathrm{~g} \mathrm{~cm}^{-3}\right)$ adalah rapat massa Au. Fungsi respon detektor SSS dapat ditentukan melalui iradiasi berkas neutron monokromatik yang divariasi dari energi rendah $\left(10^{-9} \mathrm{MeV}\right)$ hingga energi tinggi $\left(>10^{2} \mathrm{MeV}\right)$. Namun cara ini tidak mudah karena penyediaan sumber neutron monokromatik cukup rumit. Ada cara lain untuk mendapatkan nilai fungsi respon detektor SSS yaitu melalui simulasi. Teknik ini sangat bergantung pada fungsi respon yang digunakan untuk lingkup spektrometer yang biasanya dihitung dengan cara Monte Carlo (MC) menggunakan program, seperti Monte Carlo N-Particle (MCNP) [8], the FLUktuierende KAskade (FLUKA) [9], Particle and Heavy lon Transport System (PHITS) [10], dan GEometry ANd Tracking (GEANT4) [11]. Penggunaan varian dari program MCNP untuk menghitung fungsi respon detektor neutron telah dilakukan oleh Mares dan Schraube (1994) dengan menggunakan MCNP4, Mazrou, dkk dengan menggunakan MCNP5, dan Decker dan tim (2017) dengan menggunakan MCNP6 [12-14 ]. Varian dari program MCNP yang merupakan pengembangan dari era MCNP4 hingga MCNP6 yakni MCNPX adalah yang digunakan dalam penelitian ini untuk menghitung fungsi respon detektor. Contoh hasil perhitungan fungsi respon untuk setiap keping emas di dalam detektor SSS yang diperoleh melalui simulasi MCNPX diperlihatkan pada Gambar 4. Untuk simulasi neutron dengan energi di bawah $20 \mathrm{MeV}$ dihitung berdasarkan data tampang lintang eksperimental, sedangkan untuk energi di atas $20 \mathrm{MeV}$ dihitung berdasarkan model teoretik nuklir untuk interaksi neutron dengan materi $[15,16]$.

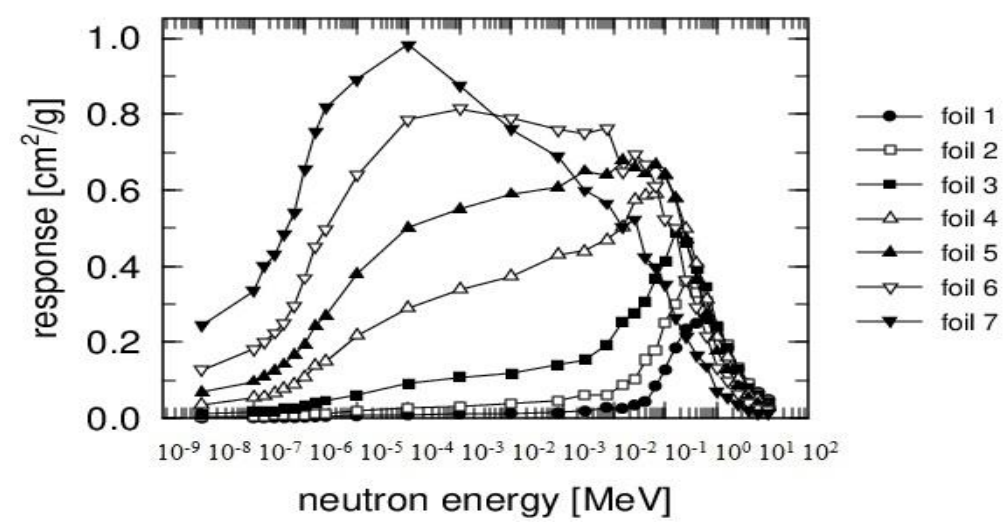

Gambar 4. Contoh hasil perhitungan fungsi respon tiap keeping emas di dalam detektor SSS [5]. 
Perangkat SSS dengan 7 detektor keping emas $\left({ }^{197} \mathrm{Au}\right)$ ditempatkan tepat pada posisi sampel radiografi dan selanjutnya diiradiasi selama 3 jam. Posisi detektor keping emas disusun paralel atau sejajar dengan arah berkas neutron datang. Jika pengukuran dilakukan dengan kondisi detektor keping emas arah tegak lurus dengan arah berkas datang maka akan menimbulkan perbedaan fluks yang terukur sebesar $3,5 \%[7]$.

Karena waktu paruh ${ }^{198} \mathrm{Au}$ adalah 2,69 hari, maka untuk mencapai aktivitas jenuh diperlukan iradiasi selama sekitar $5 \times 2,69$ hari. Tentu hal tersebut tidak memungkinkan karena selain terlalu lama juga akan ada hasil samping berupa paparan radiasi gamma yang cukup besar. Oleh karena itu aktivitas jenuh keping emas $\mathrm{A}_{\text {sat }}$ diperoleh melalui perhitungan, yaitu dengan menggunakan Persamaan 3 [17]:

$A_{\text {sat }}=F A$

Dengan $A$ adalah aktivitas per satuan massa hasil cacahan keping emas dan $F$ adalah faktor konversi yang dapat dihitung dengan Persamaan 4:

$F=\frac{1}{1-2^{-\frac{t_{i T r}}{T}}}$

Dengan tirr adalah lama iradiasi, dan T adalah waktu paruh isotop ${ }^{198} \mathrm{Au}$. Dari Persamaan 4 dapat dipeoleh nilai aktivitas jenuh untuk berapapun lama iradiasi. Dengan menggunakan nilai waktu paruh ${ }^{198} \mathrm{Au}$ sebesar 2,69 hari dan iradiasi selama 3 jam maka diperoleh faktor konversi $F=31,7$.

Detektor SSS didiamkan beberapa waktu paska iradiasi untuk menurunkan paparan radiasi gamma. Dalam pengambilan keping emas di dalam detektor SSS pasca iradiasi juga perlu diperhatikan paparan gamma ruangan yang imungkin timbul akibat adanya aktivasi neutron terhadap material sekitar. Setelah dipastikan bahwa paparan radiasi gamma menurun, masing-masing detektor keping emas diambil dan dicacah menggunakan spektrometer gamma dengan posisi yang sama dengan posisi saat pencacahan sumber kalibrasi. Melalui perbandingan antara cacahan keping emas dan cacahan sumber standar maka diperoleh aktivitas detektor keping emas .

\section{HASIL DAN PEMBAHASAN}

Hasil pengukuran aktivitas dan aktivitas jenuh masing-masing keping emas yang telah diiradiasi $\left({ }^{198} \mathrm{Au}\right)$ per satuan massa dengan menggunakan spektrometer gamma diperlihatkan pada Gambar 5. Berdasarkan grafik hubungan antara aktivitas dan posisi keping emas sebagai fungsi kedalaman sebagaimana diperlihatkan pada Gambar 5 dapat diperkirakan bahwa spektrum berkas neutron yang terukur didominasi neutron termal. Hal ini dapat dilihat dari nilai tertinggi aktivitas yang terdapat pada keping emas No.1 yaitu yang posisinya berada di paling luar pada detektor SSS, yang selanjutnya menurun sebanding dengan kedalaman posisi keping emas. Karena waktu paruh ${ }^{198} \mathrm{Au}$ relatif panjang dibandingkan dengan waktu iradiasi maka jeda antara waktu iradiasi dengan waktu pencacahan tidak berpengaruh signifikan terhadap pengurangan aktivitas keping emas. Hal ini akan berbeda jika detektor yang digunakan bukan emas tetapi unsur lain yang dapat menghasilkan radioisotop dengan waktu paruh yang lebih pendek.

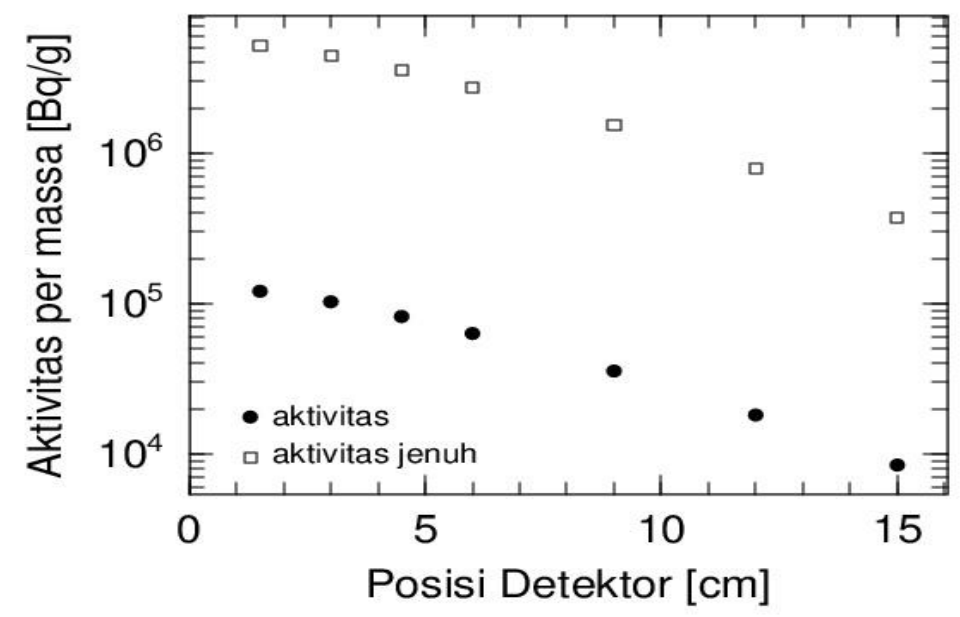

Gambar 5. Aktivitas keping emas di dalam detektor SSS paska iradiasi 


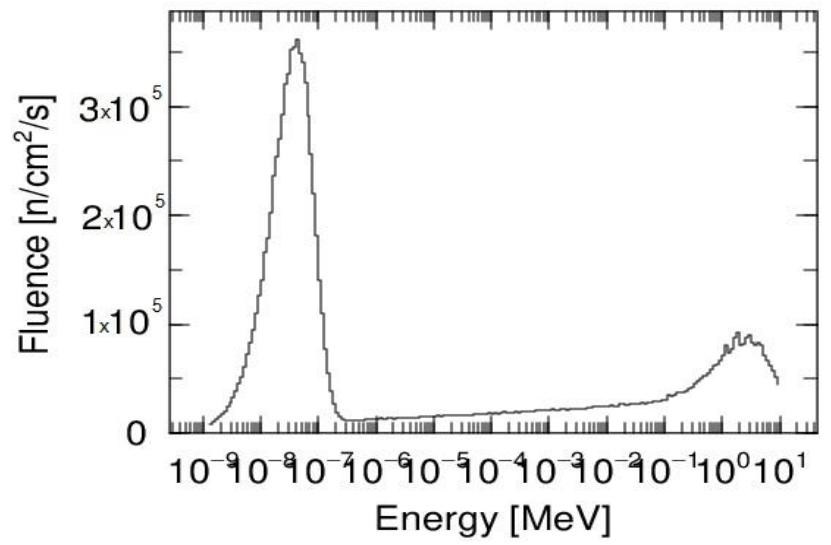

Gambar 6. Contoh hasil pengukuran spektrum neutron di ruang sampel fasilitas radiografi neutron PSTBM dengan menggunakan detektor SSS buatan BATAN.

Tabel 1. Fluks neutron di ruang sampel fasilitas radiografi neutron PSTBM - BATAN

\begin{tabular}{cccc}
\hline \multirow{2}{*}{$\begin{array}{c}\text { Jenis } \\
\text { neutron }\end{array}$} & \multicolumn{2}{c}{$\begin{array}{c}\text { Fluks neutron } \\
\left(\mathrm{cm}^{-2} \mathrm{~s}^{-1}\right)\end{array}$} & Perbedaan (\%) \\
\cline { 2 - 3 } & $\mathbf{2 0 0 8}$ & Sekarang & \\
\hline Termal & $9,2 \times 10^{6}$ & $6,14 \times 10^{6}$ & $32 \%$ \\
Epitermal & $1,42 \times 10^{6}$ & $1,18 \times 10^{6}$ & $17 \%$ \\
Cepat & Tidak terukur & $3,49 \times 10^{6}$ & - \\
\hline
\end{tabular}

Dengan aktivitas jenuh yang diperoleh dan fungsi respon yang telah dihitung maka melalui Persamaan 1 diperoleh fluks neutron sebagai fungsi energi. Contoh hasil spektrum neutron di suatu ruang sampel fasilitas radiografi netron PSTBM - BATAN diperlihatkan pada Gambar 6. Tampilan spektrum neutron pada Gambar 6 merupakan hasil unfolding dengan menggunakan program komputer UMG 3.3 dengan inputan aktivitas jenuh per massa keping emas dan data fungsi respon tiap posisi keping emas.

Berdasarkan tampilan spektrum pada Gambar 6 terlihat jelas bahwa spektrum neutron di ruang sampel radiografi PSTBM - BATAN didominasi oleh neutron termal. Pada Tabel 1 diperlihatkan prosentase neutron termal (energi $<5 \times 10^{-7} \mathrm{MeV}$ ), epitermal (energi $5 \times 10^{-7}-10^{-2} \mathrm{MeV}$ ) dan cepat $\left(>10^{-2} \mathrm{MeV}\right.$ ). Prosentase fluks neutron termal adalah $57 \%$, sementara neutron epitermal $11 \%$, dan neutron cepat $32 \%$. Jika dibandingkan dengan hasil pengukuran sebelumnya (pada tahun 2008) yang dilakukan menggunakan metode keping aktivasi emas dengan fluks termal rata-rata $9,2 \times 10^{6} \mathrm{n} \mathrm{cm}^{-2} \mathrm{~s}^{-1}$ maka terdapat penurunan fluks sebesar $32 \%$. Adapun untuk fluks neutron epitermal terdapat penurunan sebesar $17 \%$, dari sebelumnya 1,42 $\times 10^{6} \mathrm{n} \mathrm{cm}^{-2} \mathrm{~s}^{-1}$ sekarang menjadi $1,18 \times 10^{6} \mathrm{n} \mathrm{cm}^{-2} \mathrm{~s}^{-1}$.

\section{KESIMPULAN}

Penentuan spektrum neutron di fasilitas radiografi neutron reaktor G.A Siwabessy telah berhasil dilakukan dengan baik menggunakan detektor single sphere spectrometer buatan BATAN Tampilan spektrum neutron menunjukkan bahwa berkas neutron yang keluar dari tabung berkas didominasi neutron termal. Jika dibandingkan dengan pengukuran fluks neutron termal sebelumnya (pada tahun 2008) terdapat penurunan sebesar $32 \%$. Penurunan fluks tersebut diduga menjadi faktor yang berpengaruh terhadap penurunan kualitas ketajaman citra radiografi. Oleh karena itu, dengan ketersediaan data spektrum neutron di fasilitas radiografi neutron ini diharapkan dapat menjadi acuan untuk setiap perubahan pada hasil citra radiografi.

\section{UCAPAN TERIMA KASIH}

Ucapan terima kasih disampaikan kepada PSTBM - BATAN selaku pihak yang mendanai kegiatan penelitian ini. Ucapan terima kasih juga disampaikan kepada personil di laboratorium spektrometri gamma PSTBM atas bantuannya dalam pengukuran aktivitas keping-keping emas menggunakan spektrometer gamma dan juga kepada petugas proteksi radiasi di reaktor G.A Siwabessy atas bantuan pendampingan selama pengambilan data iradiasi. 


\section{DAFTAR PUSTAKA}

[1] J. CHADWICK, "The Existence of a Neutron", in Proceedings of the Royal Society A: Mathematical, Physical and Engineering Sciences 136, pp. 692-708, 1932.

[2] Suyatno, Setiawan, dan Sutiarso, "Pengukuran fluks neutron termal pada posisi sampel dari fasilitas radiografi neutron", Prosiding Pertemuan IImiah IImu dan Pengetahuan Teknologi Bahan, 2008

[3] J.M. Gómez-Ros, R. Bedogni, M. Moraleda, et al, Nucl. Instruments Methods Phys. Res. Sect. A Accel. Spectrometers, Detect. Assoc. Equip. 677, pp. 4-9, 2012..

[4] R. Bedogni, J.M. Gómez-Ros, a. Pola, et al, Nucl. Instruments Methods Phys. Res. Sect. A Accel. Spectrometers, Detect. Assoc. Equip. 714, pp.110-114, 2013.

[5] R. Tursinah, Bunawas, "Development of single sphere spectrometer with gold foil detector for neutron spectrometry", 2016 (belum diterbitkan)

[6] Reginatto M., UMG package, version 3.3, 2004.

[7] K. Amgarou, V. Lacoste, J. Instrum. 5, P09002., 2010.

[8] T.E. Booth et al., MCNP5 1.50 Release Notes, Los Alamos National Laboratory report LA-UR-08-2300, 2008.

[9] A. Fasso, A. Ferrari, J. Ranft and P.R. Sala, FLUKA: a multi-particle transport code, CERN-2005-10, INFN/TC 05/11, SLAC-R-773, 2005.

[10] K. Niita et al., PHITS: Particle and Heavy lon Transport code System, Version 2.23, JAEA-Data/Code 2010-022, 2010.

[11] GEANT4 collaboration, S. Agostinelli et al., GEANT4: a simulation toolkit, Nucl. Instrum. Meth. A 506 (2003) 250.12] A.W. Decker, S.R. McHale, M.P. Shannon, J.A. Clinton, J.W. McClory, IEEE Transactions on Nuclear Science, 62 (2015), pp. 1689 - 1694 [13] S. Semikh, S. Serre, J. L. Autran, D. Munteanu, S. Sauze, E. Yakushev, S. Rozov, Trans. Nucl. Sci., vol. 59, no. 2, pp. 303-313, 2012.

[14] H. Mazrou, Z. Idiri, T. Sidahmed, M. Allab, Journal of Radioanalytical and Nuclear Chemistry 284(2), pp. 253-263, 2010

[15] W. Rühm, V. Mares, C. Pioch, et al, Radiat. Meas. 67, pp. 24-34, 2014

[16] C. Pioch, V. Mares, E.. Vashenyuk, et al, Nucl. Instruments Methods Phys. Res. Sect. A 626, pp. 5157, 2011.

[17] R. Bedogni, A. Esposito, A. Gentile, et al, in:, Radiat. Meas., pp. 1757-1760, 2011. 